\title{
DNA REPLICATION IN TETRAHYMENA AFTER RELEASE FROM THYMIDINE STARVATION
}

by

\author{
H. A. ANDERSEN \\ JENS KEIDING
}

The Biological Institute of the Carlsberg Foundation

16 Tagensuej, 2200 Copenhagen N, Denmark

Key words: DNA replication, Thymidine starvation, Tetrahymena

Tetrahymena cells grown on a rich growth medium may be starved for thymidine by addition of methotrexate plus uridine $(\mathrm{M}+\mathrm{U})$. The effect of this treatment on replicating DNA molecules and the fate of these molecules after release from the starvation condition have been studied. Thymidine starvation during the latter half of the macronuclear S-period leads to the appearance of a DNA fraction with a buoyant density higher than that of bulk DNA. In the next cell cycle, after removal of $M+U$ by transfer of the cells to a fresh growth medium, this heavy DNA fraction persists throughout the macronuclear S-period, but it disappears during the following G2-period and is converted to a DNA fraction with relatively low buoyant density. Based on these results, it is suggested 1) that the thymidine starvation preferentially inhibits replication in regions of the DNA molecules with high dAdT base pair concentrations, 2) that the DNA molecules stalled in replication are partially single-stranded and 3) that the low buoyant density DNA fraction is formed as a consequence of a completion of these molecules to fully doublestranded DNA.

\section{INTRODUCTION}

Methotrexate plus uridine $(\mathrm{M}+\mathrm{U})$ was introduced by ZEUTHEN (26) as a specific inhibitor of DNA replication in Tetrahymena pyriformis growing in a complex medium containing thymidine. Methotrexate inhibits the endogenous synthesis of thymidine and uridine acts as an inhibitor of the incorporation of thymidine from the medium. The $M+U$ technique has proven especially useful in the study of DNA replication in heat-synchronized populations (3, 27). In this system, addition of $M+U$ in the first half of the macronuclear S-period delays the forthcoming cell division; if $\mathrm{M}+\mathrm{U}$ is introduced later in the S-period, cell division follows with- out delay (3). In the latter case a fraction of partially replicated DNA is translocated to the cytoplasm at the time of the nuclear division and stays there during the following cell cycle (2). Resumption of bulk DNA synthesis follows shortly after removal of $\mathrm{M}+\mathrm{U}$. Replication of the translocated DNA fraction starts later after completion of bulk DNA synthesis. Thus this cytoplasmic DNA fraction of nuclear origin replicates in the G2-period, and it is apparently continuing the replication which was stalled by the $\mathrm{M}+\mathrm{U}$ treatment in the previous cell cycle (4).

The present work substantiates this interpretation. A model for the effect of thymidine star- 

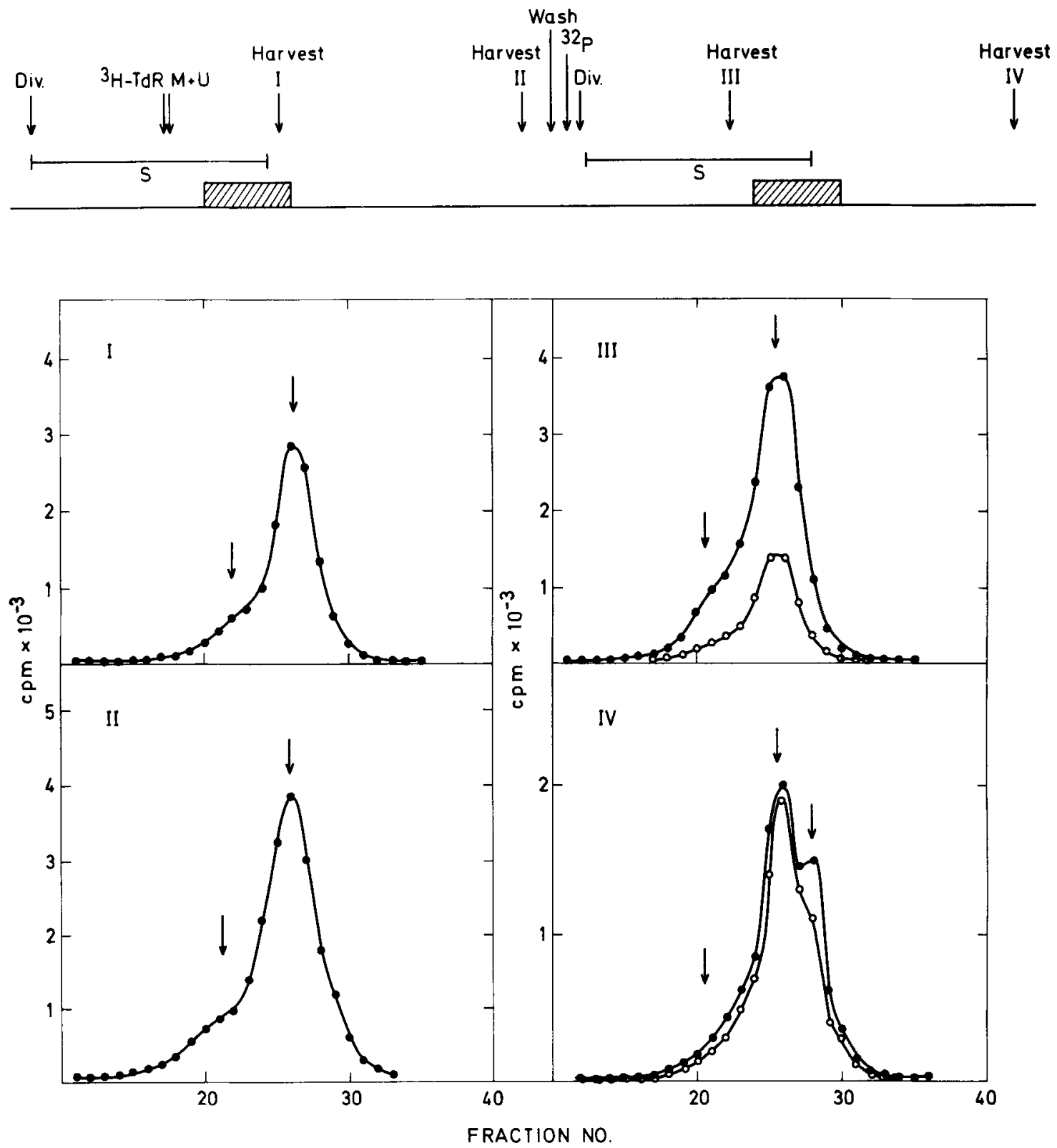

Figure 1. The plan of the experiment is shown on the top of the figure. A population was synchronized with a series of heat shocks of which nos 6 and 7 are indicated as hatched areas. In the middle of an S-period, 3-H thymidine was added and the DNA replication was inhibited by addition of $M+U$. DNA was isolated from cells harvested near the end of the S-period (I) and again near the end of the G2-period (II). The remaining cells were transferred to a normal growth medium and 32-P was added. In the next cell cycle DNA was isolated from cells harvested in the latter half of the S-period (III) and once again late in the G2-period (IV). The isolated DNA was centrifuged in neutral $\mathrm{CsCl}$-gradients, and the results are shown in the lower part of the figure (I-IV).

$(\bullet)$ : 3-H thymidine, (o): 32-P. It may be seen that after $\mathrm{M}+\mathrm{U}$ inhibition of the replication, a fraction of the pulse labelled DNA has a relatively high buoyant density (I and II), and that this high buoyant density fraction persists through the S-period of the following cell cycle, after $M+U$ has been removed (III). The high buoyant density fraction of the pulse labelled DNA disappears in the G2-period of the second cell cycle and instead a low buoyant density fraction of the pulse labelled DNA appears (IV). 
vation on replicating DNA molecules will be presented. There is no evidence of repair replication of DNA during or after thymidine starvation.

\section{MATERIALS AND METHODS}

Tetrahymena pyriformis, amicronucleate strain GL was grown as previously described (3, 6) and synchronized by treatment with one heat shock per cell cycle as described by ZEUTHEN (28).

Inhibition of the DNA replication was obtained by addition of methotrexate (gift from Cyanamid Overseas Corporation, USA, Copenhagen Division) and uridine at final concentrations of 0.05 and $20 \mathrm{mM}$, respectively (26).

For long-term labelling of DNA with either 3-H thymidine or 32-P orthophosphate these compounds were added at the time of inoculation of the culture. $0.05 \mathrm{mCi} 3-\mathrm{H}$ thymidine or $0.1 \mathrm{mCi} 32-\mathrm{P}$ orthophosphate were added per $150 \mathrm{ml}$ culture. For pulse labelling experiments the radioactivities were increased to $0.1 \mathrm{mCi}$ of 3- $\mathrm{H}$ thymidine and $0.5 \mathrm{mCi} 32-\mathrm{P}$ orthophosphate. The cesium chloride gradient analysis of DNA was performed as described previously (6).

Incubation of DNA with nuclease SI (Sigma, $\mathrm{N}$-5255) was performed in "nuclease buffer", $\mathrm{pH}$ 4.5 (30 $\left.\mathrm{mMNa}_{2} \mathrm{Ac}, 10 \mathrm{~mm} \mathrm{NaCl}, 0,3 \mathrm{mM} \mathrm{ZnSO}_{4}\right)$. The $2 \mathrm{ml}$ sample containing about $30 \mu \mathrm{g}$ DNA was incubated with 1 Kunitz unit for 30 minutes at $37^{\circ} \mathrm{C}$.

\section{RESULTS}

A synchronized population was pulse labelled with $3-\mathrm{H}$ thymidine in the latter half of the S-period, and shortly thereafter the DNA replication was inhibited by addition of methotrexate plus uridine $(\mathrm{M}+\mathrm{U})$. Prior to the next cell division, $\mathrm{M}+\mathrm{U}$ was removed by wash of the cells to a fresh growth medium to permit DNA replication to take place in the next cell cycle. After $\mathrm{M}+\mathrm{U}$ had been removed, 32-P phosphate was added to label the DNA synthesized in the second cell cycle. The experimental schedule is shown schematically in the upper part of figure
1. DNA was isolated from cells harvested at various times in the first cell generation in the presence of $\mathrm{M}+\mathrm{U}$ and again in the second cell cycle when new DNA replication took place. The DNA was centrifuged in neutral cesium chloride gradients and the results from four such gradients are shown in figure 1 (samples were harvested at the times indicated by arrows I-IV in the upper part of the figure). It may be seen that tritiated thymidine incorporated into DNA at a time when $\mathrm{M}+\mathrm{U}$ inhibits the replication is found in DNA not only of normal buoyant density, but also in a fraction of DNA with relatively high buoyant density (gradients I and II). After removal of $\mathrm{M}+\mathrm{U}$, this heavy
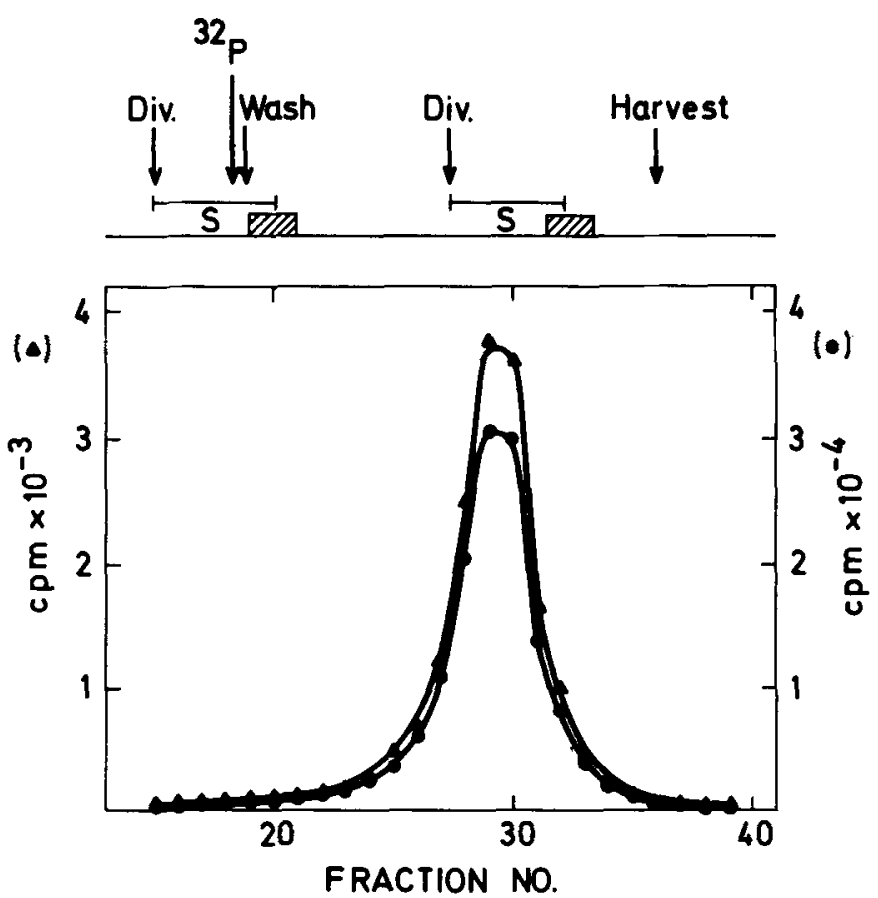

Figure 2. The plan of the experiment is shown on top of the figure. The cells were grown in the presence of 3-H thymidine for several generations. In the latter half of a synchronized S-period 32-P labelled phosphate was added to pulse label DNA in replication, and the pulse labelling was terminated by transfer of the cells to a fresh growth medium. The cells were harvested in the G2-period of the following cell cycle. DNA was centrifuged in a neutral $\mathrm{CsCl-gradient}$ and the result is shown in the lower part of the figure. $(\bullet)$ long term 3-H labelling, cpm. (A): 32-P pulse labelling, cpm. It may be seen that the pulse labelled DNA has the same buoyant density as the bulk DNA. 
DNA fraction persists during the S-period of the next cell cycle (gradient III), but it disappears in the following G2-period and at the same time a fraction of relatively low buoyant density appears (gradient IV). Figure 2 shows the results of a control experiment in which no $\mathrm{M}+\mathrm{U}$ was added. The cells were labelled
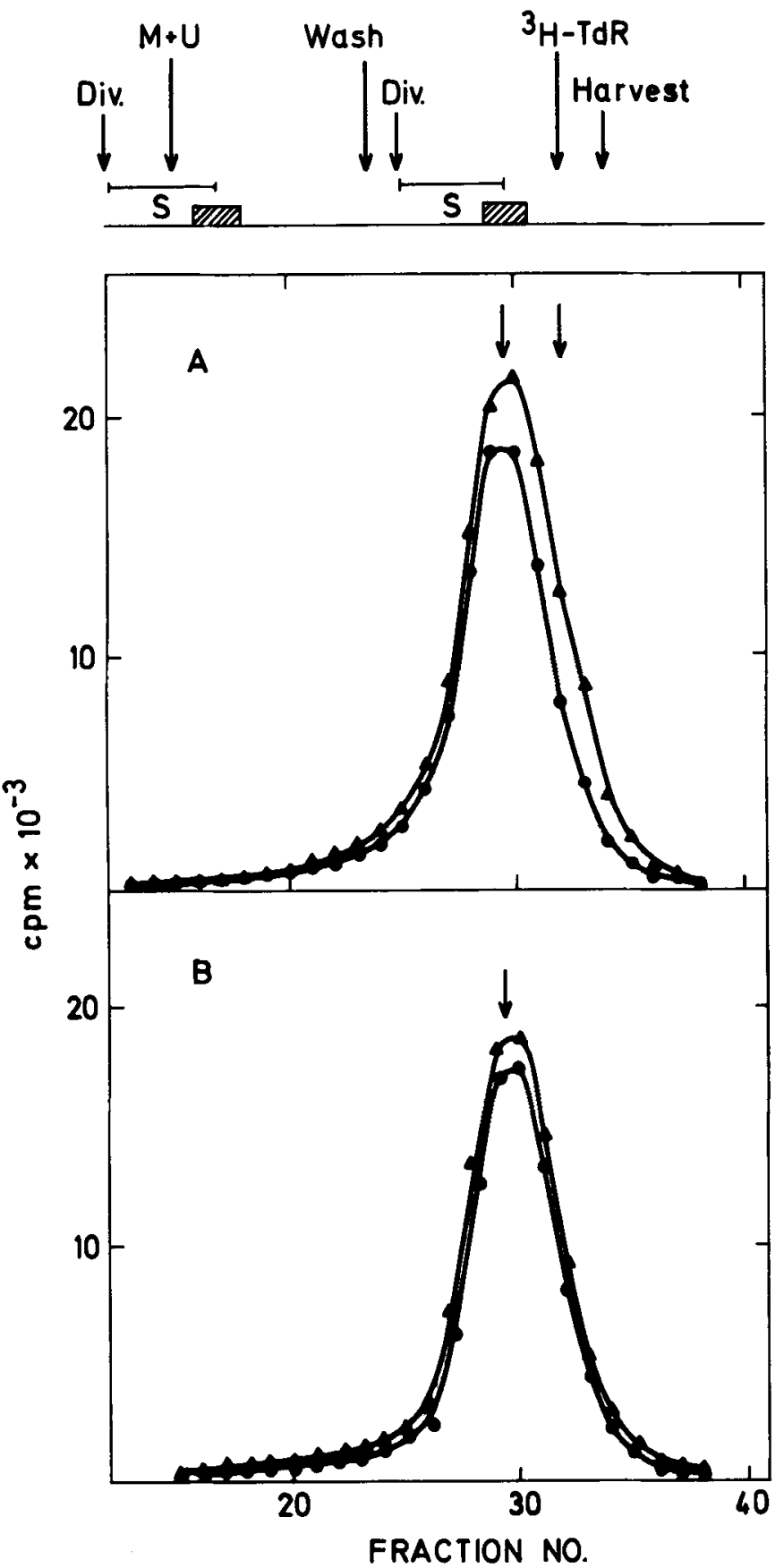

uniformly with tritiated thymidine and pulse labelled with 32-P phosphate in the latter half of a synchronized S-period. DNA was isolated from cells harvested in the G2-period of the following cell cycle. It may be seen that no light pulse labelled DNA fraction is present in the subsequent cell cycle in this experiment.

Thus in cells treated with $\mathrm{M}+\mathrm{U}$ in an $\mathrm{S}$ period, a DNA fraction with relatively high buoyant density is formed. This fraction persists during the rest of the first cell cycle; it finally disappears during the G2-period of the second cell cycle, and at the same time a DNA fraction with a low buoyant density appears.

It has previously been reported that a macronuclear DNA fraction which is blocked in replication in one cell cycle by $\mathrm{M}+\mathrm{U}$ continues to replicate in the G2-period in the following cell cycle provided $\mathrm{M}+\mathrm{U}$ is removed at the time of the intervening cell division (4). To ascertain whether it was possible to label the low buoyant density DNA fraction during its synthesis in the G2-period of the second cell cycle, the following experiment was performed. The experimental schedule is shown in the upper part of figure 3. In this experiment DNA was uniformly labelled with 32-P overnight and $M+U$ was added in the second half of a synchronous S-period. At the time of the subsequent division, the cells were transferred to normal growth medium and

Figure 3. The plan of the experiment is shown on top of the figure. DNA was uniformly labelled with 32-P phosphate by growing the cells for several generations in the presence of this compound. Around the middle of a synchronized S-period, $\mathrm{M}+\mathrm{U}$ was added to inhibit DNA replication. $M+U$ was removed shortly before the next cell division, and DNA in replication in the G2-period of the next cell cycle was labelled by addition of 3-H thymidine. The cells were harvested 30 minutes later and DNA was centrifuged in a neutral $\mathrm{CsCl}$-gradient. The result may be seen in frame $\mathrm{A}$. (๑): long term 32-P labelling, cpm. (A): 3-H thymidine pulse labelling, cpm. It may be seen that DNA synthesized in the G2-period after $\mathrm{M}+\mathrm{U}$ treatment in the S-period of the preceding cell cycle contains a fraction of low buoyant density. The results in frame B show DNA isolated from a control population treated as described for (A) except no $M+U$ was added. In this case no low buoyant density DNA is formed. 
finally pulse labelled with 3-H thymidine during 30 minutes of the G2-period in the second cell cycle. The result is shown in figure $3 \mathrm{~A}$. The 32-P labelled DNA forms a single band in the cesium chloride gradient, whereas the $3-\mathrm{H}$ labelled DNA contains a light DNA fraction corresponding to that shown in figure 1 , IV. Figure $3 \mathrm{~B}$ shows a similar experiment where the addition of $\mathrm{M}+\mathrm{U}$ was omitted. Under these conditions 3-H thymidine is not incorporated into a light DNA fraction.

Is the heavy DNA fraction which is accumulated in the presence of $\mathrm{M}+\mathrm{U}$ in the first cell cycle identical to the one which in the G2period of the subsequent cell cycle is converted to a light density DNA fraction? To answer this question, a DNA fraction was BUdR labelled prior to the addition of $\mathrm{M}+\mathrm{U}$ as indicated in figure 4. The experimental schedule is shown in the upper part of the figure. The DNA was uniformly labelled with $3-\mathrm{H}$ thymidine, and in a synchronized S-period, with an interval of 2-5 minutes, 32-P labelled orthophosphate, BUdR and $\mathrm{M}+\mathrm{U}$ were added. Few minutes later all label was removed by wash of the cells to a fresh medium containing only $M+U$. Shortly before the forthcoming cell division, a new wash to fresh medium followed to remove the $\mathrm{M}+\mathrm{U}$, and late in the next cell cycle DNA was isolated and centrifuged in cesium chloride. Under these labelling conditions 32-P and BUdR are incorporated solely in DNA molecules which were under replication at or shortly before the addition of $\mathrm{M}+\mathrm{U}$. All other DNA molecules are labelled exclusively with $3-\mathrm{H}$. As it appears from the results shown in figure 4, no light DNA fraction is present in the DNA isolated in this experiment; only DNA with a buoyant density similar to or higher than that of bulk DNA could be detected. The absence of a light DNA fraction in this experiment suggests that DNA which had finished replication prior to the addition of BUdR is not part of the DNA fraction replicating in the G2-period of the second cell cycle.

In an additional experiment DNA was pulse labelled with 3-H thymidine in the G2-period as described in the experiment shown in figure 3, and prelabelled with BUdR prior to the $\mathrm{M}+\mathrm{U}$ treatment in the S-period of the preceding cell cycle. No light DNA fraction could be seen under these labelling conditions, again suggesting that density labelling of the DNA which is blocked in replication prevents the formation of the light DNA fraction in the G2-period of the subsequent cell cycle (data are not shown).

Based on these experiments it is therefore suggested that the DNA fraction which appears in the first cell cycle as a heavy density fraction is converted in the G2-period of the second cell cycle to a light DNA fraction and that this frac-
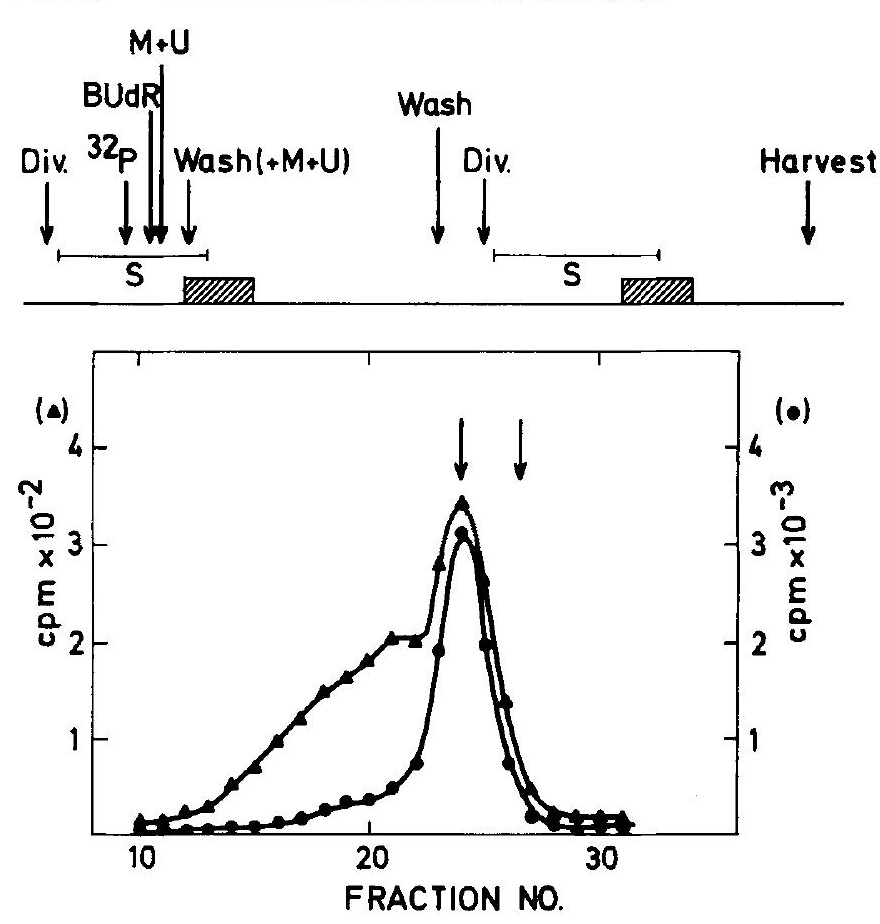

Figure 4. The plan of the experiment is shown on top of the figure. DNA was uniformly labelled with 3-H thymidine. In a synchronized S-period 32-P labelled phosphate, BUdR and $M+U$ were added. 32-P phosphate and BUdR were removed from the culture by transfer of the cells to a fresh growth medium containing $\mathrm{M}+\mathrm{U} . \mathrm{M}+\mathrm{U}$ was removed shortly before the next cell division and the cells were harvested late in the next cell cycle. The DNA was isolated and centrifuged in a neutral $\mathrm{CsCl}$-gradient and the results are shown in the lower part of the figure. (•): long term 3-H thymidine labelling, cpm. (4): 32-P phosphate pulse labelling, cpm. It appears that when the DNA which was stalled in replication by $\mathrm{M}+\mathrm{U}$ contains BUdR no light DNA is present. On the contrary, DNA labelied this way forms a heavy buoyant density shoulder in the gradient. 
few minutes (3). The results presented in the present paper show that part of the DNA molecules trapped in replication by lack of thymidine appears to be partially single-stranded. In accordance with this, JOHNSON, and WESTERGAARD have recently reported the formation of DNA containing single-stranded regions after $\mathrm{M}+\mathrm{U}$ treatment of Tetrahymena (16).

Conflicting reports have been presented with respect to the effect of thymidine starvation on the integrity of the DNA of Tetrahymena. In short time experiments $M+U$ seems to be a fairly specific inhibitor of DNA synthesis. Soon after release from $\mathrm{M}+\mathrm{U}$ an apparently normal continuation of DNA synthesis has been reported (22). Moreover, it has recently been observed that this DNA synthesis, like the DNA synthesis in untreated cells, is highly sensitive to hydroxyurea, whereas the DNA synthesis occurring in cells after u.v. treatment is insensitive to hydroxyurea (17). In eukaryote cells hydroxyurea is known to inhibit replicative DNA synthesis, but it has no effect on repair synthesis (9). No secondary effects of $\mathrm{M}+\mathrm{U}$ such as damage to the DNA has been recorded in Tetrahymena grown on proteose peptone. In an abstract WESTERGAARD et al. have claimed, on the other hand, that $M$ alone causes excision-repairable damage to the DNA of Tetrahymena when they are grown in a chemically defined medium (24). Referring to this abstract it has repeatedly been postulated that thymidine starvation leads to damage of DNA in Tetrahymena $(23,25)$. However, experimental support for this statement is lacking. On the contrary the recent paper by JOHNSON and WESTERGAARD shows that treatment with $\mathrm{M}+\mathrm{U}$ for as long as 18 hours causes no significant damage to Tetrahymena DNA; after refeeding with either BUdR or TdR the DNA molecules appeared to continue a normal replication (16).

The results in this paper also argue against repair synthesis in Tetrahymena after $\mathrm{M}+\mathrm{U}$ treatment. The formation of a DNA fraction of low buoyant density is an unlikely consequence of repair of DNA. ANDERSEN and ZEUTHEN have shown (5) that in heat synchronized cells the DNA replication sequence in one cell generation is not repeated in the following cell generation. Thus it is difficult to envisage that a DNA fraction of low buoyant density should be damaged at a distinct time in one cell cycle and repaired in the following cycle. Any pulse labelled DNA fraction isolated from untreated Tetrahymena cells during the macronuclear S-period has the same buoyant density as bulk DNA. Therefore, any fraction stalled in replication by $\mathrm{M}+\mathrm{U}$ and later released from this treatment should in theory after completion of replication again appear as DNA of normal density. The formation of light DNA (dAdT rich) after release from $\mathrm{M}+\mathrm{U}$ can be explained, however, as an uneven distribution of label in different parts of the newly formed DNA. Tetrahymena DNA contains about $74 \%$ dAdT base pairs (12) and oligo-dAdT-stretches occur rather frequently $(8,19)$. It is to be expected that the replication of DNA areas rich in dAdT will be especially sensitive to thymidine starvation. The consequence of this would be accumulation of partially single-stranded molecules of the type schematically presented in figure 6 . After release from $M+U$ new label (3-H or 32-P) is preferentially incorporated into DNA regions with high frequency of dAdT base pairs. During isolation of the cellular DNA the originally very long molecules are partly broken into smaller pieces, and the dAdT rich DNA pieces thus dominate over $\mathrm{dCdG}$ rich in the fraction of pulse labelled DNA. The buoyant density of DNA decreases when the percentage of dAdT base pairs increases (21). The appearence of a light DNA fraction in the G2-period of cells treated with $\mathrm{M}+\mathrm{U}$ in the S-period of the previous cell

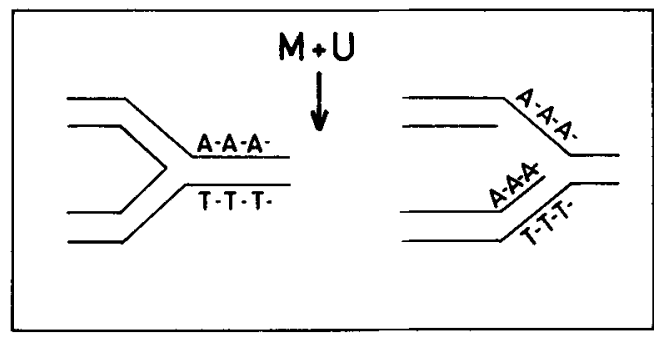

Figure 6. A schematic illustration of the proposed effect of $\mathrm{M}+\mathrm{U}$ on replicating DNA. The replication is blocked in a region of the molecule with relatively high concentration of dAdT base pairs, leaving partially replicated molecules with single-stranded regions of high $d A$ content. 
cycle may therefore be explained as the result of the synthesis of normal double-stranded DNA in which label is unevenly distributed.

Previously published results have indicated that DNA stalled in replication by $\mathrm{M}+\mathrm{U}$ addition in the latter half of the marcronuclear $S$-period continues replication in the cytoplasm during the G2-period of the following cell cycle (6). The experiments reported in the present paper support the previous with respect to the timing of this phenomenon within the cell cycle. In the above series of experiments we have not localized the synthesis within the cell, but we assume, based on earlier results, that the G2period replication here observed takes place in the cytoplasm.

\section{ACKNOWLEDGEMENT}

The authors wish to thank Miss BIRGIT HELT-HANSEN most gratefully for expert technical assistance.

The work was supported by a grant to JENS KEIDING from the Danish Natural Science Research Council.

\section{REFERENCES}

1. Alberts, B. M. \& L. Frey: $T_{4}$ bacteriophage gene 32: a structural protein in the replication and recombination of DNA. Nature 227, 1313-1317 (1970)

2. ANDERSEN, H. A.: Induced elimination of DNA from the macronucleus of Tetrahymena pyriformis. Exptl. Cell Res. 74, 610-613 (1972)

3. ANDERSEN, H. A.: Requirements for DNA replication preceding cell division in Tetrahymena pyriformis. Exptl. Cell Res. 75, 89-94 (1972)

4. ANDERSEN, H.A.: Replication of macronuclear DNA in the cytoplasm of Tetrahymena pyriformis. J. Cell Sci. 14, 289-300(1974)

5. ANDERSEN, H. A. \& E. ZEUThen: DNA replication sequence in Tetrahymena is not repeated from generation to generation. Exptl. Cell Res. 68, 309-314 (1971)

6. ANDERsen, H. A., C. F. Brunk \& E. Zeuthen: Studies on the DNA replication in heat synchronized Tetrahymena pyriformis. Compt. Rend. Trav. Lab. Carlsberg 38, 123-131 (1970)

7. Banks, G. R. \& A. Spanos: The isolation and properties of a DNA-unwinding protein from Ustila- go maydis. J. Mol. Biol. 93, 63-77 (1975)

8. BRUNK, C. F.: Distribution of dimers in ultraviolet-irradiated DNA. Nature, New Biology 241, 74-76 (1973)

9. Cleaver, J. E.: Repair replication of mammalian cell DNA: effects of compounds that inhibit DNA synthesis or dark repair. Rad. Res. 37, 334-348 (1969)

10. Edenberg, H. J. \& J. A. Huberman: Eukaryotic chromosome replication. Ann. Rev. Genet. 9, 245-284 (1975)

11. Flamm, W. G., M. Mocallum \& P. M. В. WALKER: The isolation of complementary strands from a mouse DNA fraction. Proc. Natl. Acad. Sci. USA 57, 1729-1734(1967)

12. Flavell, R. A. \& I. G. Jones: Mitochondrial deoxyribonucleic acid from Tetrahymena pyriformis and its kinetic complexity. Biochem. J. 116, 811-817 (1970)

13. Herrick, G. \& B. Alberts: Purification and physical characterization of nucleic acid helixunwinding protein from calf thymus. J. Biol. Chem. 251, 2124-2132 (1976)

14. HotTA, Y. \& H. STERN: A DNA-binding protein in meiotic cells of Lilium. Dev. Biol. 26, 87-99 (1971)

15. Huberman, J. A.\& A. D. Riggs: On the mechanism of DNA replication in mammalian chromosomes. J. Mol. Biol. 32, 327-341 (1968)

16. Johnson, B. \& O. WestergaARD: Accumulation of replicative DNA intermediates in Tetrahymena after excision-repairable damage to DNA. Europ. J. Biochem. 62, 345-352 (1976)

17. KEIDING, J.: Ph.D. Thesis, University of Copenhagen (1977)

18. Kriegstein, H. J. \& D. S. Hogness: Mechanism of DNA replication in Drosophila chromosomes: structure of replication fork and evidence for bidirectionality. Proc. Natl. Acad. Sci. USA 71, 135-139 (1974)

19. Mol, J. N. M., R. A. Flavell \& P. Borst: The presence of (dAdT) $20-25$ tracts in the DNA of primitive eukaryotes. Nucl. Acid Res. 3, 2367-2377 (1976)

20. NExø, B. A.: Indholdet af ribo- og deoxyribonukleotid triphosphater i Tetrahymena kulturer. Thesis (University of Copenhagen) (1973)

21. Schildkraut, C. L., J. Marmur \& P. Doty: Determination of the base composition of deoxyribonucleic acid from its buoyant density in $\mathrm{CsCl}$ J. Mol. Biol. 4, 430-443 (1962)

22. Villadsen, I. S. \& E. ZeUthen: Synchronization of DNA synthesis in Tetrahymena populations by temporary limitation of access to thymine compounds. Exptl. Cell Res. 61, 302-310 (1970) 
23. WestergaARd, O.: Separation of two DNA polymerase fractions from Tetrahymena cells after excision-repairable damage to DNA. Biochim. Biophys. Acta 213, 36-44 (1970)

24. Westergatrd, O., R. E. Pearlman \& C. F. BRUNK: DNA polymerase activity in vitro during excision-repair of DNA in Tetrahymena. Abstr. Commun. 5th Meet. Fed. Eur. Biochem. Soc., Prague p.93 (1968)

25. Westergatrd, O. \& R. E. Pearlman: DNA polymerase in methotrexate plus uridine treated
Tetrahymena. Exptl. Cell Res. 54, 309-313(1969)

26. ZEUTHEN, E.: Thymidine starvation by inhibition of uptake and synthesis of thymine compounds in Tetrahymena. Exptl. Cell Res. 50, 37-46 (1968)

27. ZeUTHEN, E.: Independent synchronization of DNA synthesis and of cell division in same culture of Tetrahymena cells. Exptl. Cell Res. 61, 311-325 (1970)

28. ZEUTHEN; Synchrony in Tetrahymena by heat shocks spaced a normal cell cycle apart. Exptl. Cell Res. 68, 49-60 (1971) 